\title{
On the Relation between the Boreal Spring Position of the Atlantic Intertropical Convergence Zone and Atlantic Zonal Mode ${ }^{\mathscr{b}}$
}

\author{
VIJAY POTTAPINJARA a AND M. S. GIRISHKUMAR \\ Indian National Centre for Ocean Information Services, Hyderabad, India \\ R. MURTUGUdDE \\ Earth System Science Interdisciplinary Centre, University of Maryland, College Park, College Park, Maryland \\ K. ASHOK \\ Centre for Earth, Ocean and Atmospheric Sciences, University of Hyderabad, Hyderabad, India

\section{RAVICHANDRAN} \\ Indian National Centre for Ocean Information Services, Hyderabad, and National Centre for Polar and \\ Ocean Research, Goa, India
}

(Manuscript received 19 September 2018, in final form 4 April 2019)

\begin{abstract}
Previous studies have talked about the existence of a relation between the Atlantic meridional mode (AMM) and Atlantic zonal mode (AZM) via the meridional displacement of the intertropical convergence zone (ITCZ) in the Atlantic during boreal spring and the resulting cross-equatorial zonal winds. However, why the strong relation between the ITCZ (or AMM) and zonal winds does not translate into a strong relation between the ITCZ and AZM has not been explained. This question is addressed here, and it is found that there is a skewness in the relation between ITCZ and AZM: while a northward migration of ITCZ during spring in general leads to a cold AZM event in the ensuing summer, the southward migration of the ITCZ is less likely to lead to a warm event. This is contrary to what the previous studies imply. The skewness is attributed to the Atlantic seasonal cycle and to the strong seasonality of the AZM. All those cold AZM events preceded by a northward ITCZ movement during spring are found to strictly adhere to typical timings and evolution of the different Bjerknes feedback components involved. It is also observed that the causative mechanisms of warm events are more diverse than those of the cold events. These results can be expected to enhance our understanding of the AZM as well as that of chronic model biases and contribute to the predictability of the Indian summer monsoon through the links between the two as shown in our earlier studies.
\end{abstract}

\section{Introduction}

It is well known that the interannual variability of the Indian summer monsoon rainfall (ISMR) is governed

Supplemental information related to this paper is available at the Journals Online website: https://doi.org/10.1175/JCLI-D-180614.s1.

\footnotetext{
${ }^{a}$ Additional affiliation: Centre for Earth, Ocean and Atmospheric Sciences, University of Hyderabad, Hyderabad, India.
}

Corresponding author: Vijay Pottapinjara, vijay.p@incois.gov.in by both internal dynamics and external factors such as El Niño-Southern Oscillation (ENSO) (Sikka 1980; Keshavamurty 1982; Mooley and Parthasarathy 1984; Philander et al. 1989; Webster et al. 1998) and the Indian Ocean dipole (IOD)/zonal mode (IODZM; Behera et al. 1999; Ashok et al. 2001; Slingo and Annamalai 2000), the dominant interannual modes in the tropical climate. The Atlantic zonal mode (AZM), akin to but weaker than ENSO (Zebiak 1993), is active during boreal summer (June-August) and contemporaneous with the Indian summer monsoon (ISM). It has been shown to influence the ISMR by recent studies (Kucharski et al. 2008, 2009; Wang et al. 2009; Pottapinjara et al. 2014; 
Richter et al. 2014; Pottapinjara et al. 2016; Kucharski et al. 2016; Yadav 2017). The warm (cold) phase of AZM tends to reduce (enhance) rainfall over India with its effect being especially significant when there is no cooccurring ENSO event (Wang et al. 2009; Pottapinjara et al. 2014). On the other hand, the AZM can sow the seeds for the development of an ENSO event (Rodríguez-Fonseca et al. 2009; Ham et al. 2013; Martin et al. 2014; Kucharski et al. 2016). Therefore, an enhanced understanding of different causative mechanisms of AZM will aid in better prediction of the ISM as well as a better understanding of ENSO dynamics, among other things.

In addition to the AZM, the interannual variability in the tropical Atlantic is dominated by the Atlantic meridional mode (AMM; Nobre and Shukla 1996; Chiang and Vimont 2004; Xie and Carton 2004). AMM, another interannual mode in the tropical Atlantic, is active during boreal spring. It is characterized by SST anomalies of opposite sign on either side of the equator (see data and methods section for the definition). The two modes, AMM (active in boreal spring) and AZM (active in boreal summer), are related via the meridional displacement of the intertropical convergence zone (ITCZ) in boreal spring (Servain et al. 1999; Murtugudde et al. 2001). These early studies indicate that the anomalous meridional movement of ITCZ during spring is an important precursor to the AZM. Chiang et al. (2002) attribute the variability of the ITCZ position in the Atlantic to two factors, namely, the cross-equatorial SST gradient (or AMM) and the remote forcing from the equatorial Pacific through ENSO. The AMM is likely not a completely independent mode. SSTs in the tropical North Atlantic (TNA), the northern lobe of AMM, can be influenced by the North Atlantic Oscillation (e.g., Czaja et al. 2002; Yang et al. 2018) and ENSO (e.g., Huang 2004; Amaya and Foltz 2014). The TNA SST warming occurs a season after the mature phase of ENSO warm events (Enfield and Mayer 1997; Giannini et al. 2000; Yang et al. 2018). The role of AMM in the meridional movement of the ITCZ during spring has already been discussed in previous studies (Servain et al. 1999; Murtugudde et al. 2001). Apart from reiterating the importance of AMM, Chiang et al. (2002) suggest that ENSO can also modulate the meridional position of the ITCZ during spring in the Atlantic through Walker circulation. An El Niño peaking in boreal winter suppresses convection over equatorial Atlantic in the following spring via the descending branch of anomalous Walker circulation. Without presenting the details, they note that as a secondary effect of the suppression of rainfall over the equatorial Atlantic, the ITCZ moves north. Lee et al. (2008) stress the importance of persistence of the tropical Pacific forcing into boreal spring in determining TNA SST and thus the ITCZ movement. García-Serrano et al. (2017) suggest that ENSO influences TNA SST through a remote secondary Gilltype mechanism. In this mechanism, for example, a decaying El Niño that persists into boreal spring can suppress the convection over the deep tropical Atlantic and generate two upper-level cyclonic circulations as though a heat sink is located over the same region. So, the Atlantic ITCZ during spring can be affected directly (without much time lag) by AMM and directly via convective processes by a decaying ENSO (Neelin and $\mathrm{Su} 2005$ ), or indirectly (with a time lag of few months) via TNA variability (Czaja et al. 2002; Czaja and Frankignoul 2002; Yang et al. 2018; Wu and Liu 2002).

As mentioned earlier, the meridional movement of the Atlantic ITCZ during spring is an important precursor to the AZM. The relation between the two concisely is that the spring ITCZ migration, through the resulting spring zonal wind anomalies over the equator, triggers the Bjerknes feedback and leads to an AZM event in the following summer. Bjerknes feedback involves western equatorial Atlantic zonal wind anomalies forcing thermocline depth variations in the eastern equatorial Atlantic, which then influence the SST anomalies in the east, which in turn positively feedback to the wind anomalies (Keenlyside and Latif 2007). The correlation between the ITCZ position during spring and concurrent western equatorial Atlantic zonal winds is -0.82 , significant at the $5 \%$ level (see Table 1 and data and methods section for details). Given the apparent criticality of the spring western equatorial Atlantic zonal winds in the formation of an AZM event, it may appear that the relation between the spring ITCZ and AZM is quite robust. However, the correlation between the spring ITCZ and Atlantic 3 (ATL3) SST index (see data and methods section for definition) that characterizes the AZM reduces to a moderate -0.34 , still significant at the $5 \%$ level but just above the threshold of significance (Table 1). This raises an interesting set of questions: What causes the drop in correlations? Is there a limiting factor in the Bjerknes feedback chain that may explain the drop? Does the relation hold equally well for both cold and warm AZM events? In other words, is the ITCZ-AZM relation symmetric? The question of symmetry is motivated by a result from ENSO diversity studies that highlight that there is more diversity in the warm events in the tropical Pacific (El Niño), and differences between the cold events (La Niña) are subtle (Kug and Ham 2011; Ren and Jin 2011; Capotondi et al. 2015; Chen et al. 2015; Ashok et al. 2017; Timmermann et al. 2018). A few recent reports make a passing mention of this knowledge gap, as discussed below. 
TABLE 1. Correlations between different parameters averaged over different months (MAM: March-May; AMJ: April-June; MJJ: May-July; JJA: June-August). AMM: Atlantic meridional mode; AZM: Atlantic zonal mode; zonal wind: central to western equatorial Atlantic zonal winds; EEA HC: eastern equatorial Atlantic heat content; WEA HC: western equatorial Atlantic heat content; ITCZ: intertropical convergence zone. See text (section 3a) and Fig. 2 for the regions over which different parameters are averaged.

\begin{tabular}{lclr}
\hline \hline & Correlation coefficient & & Correlation coefficient \\
\hline MAM AMM vs MAM ITCZ & 0.81 & MAM AMM vs JJA ATL3 & -0.31 \\
MAM ITCZ vs MAM zonal wind & -0.82 & MAM ITCZ vs JJA ATL3 & -0.34 \\
MAM zonal wind vs AMJ EEA HC & 0.65 & MAM zonal wind vs JJA ATL3 & 0.54 \\
AMJ EEA HC vs MJJ WEA HC & -0.69 & AMJ EEAHC vs JJA ATL3 & 0.50 \\
& & MJJ WEAHC vs JJA ATL3 & -0.43 \\
\hline
\end{tabular}

Notably, extending the earlier studies (Servain et al. 1999; Murtugudde et al. 2001), a recent study by Foltz and McPhaden (2010) shows that the equatorial zonal winds caused by positive AMM (anomalously warm north and/or cold south), force off-equatorial oceanic Rossby waves that are reflected as downwelling Kelvin waves from the western equatorial Atlantic opposite in sign to the directly forced Kelvin waves. The reflected downwelling Kelvin waves in turn terminate the AZM warm event toward the end of summer. The conclusion of Foltz and McPhaden (2010) that AMM and AZM are related is from a correlation analysis that is insensitive to the asymmetry, if any, in the relation. With regard to differences between cold and warm AZM events during their lifetime, Lübbecke and McPhaden (2017) show, based on a composite analysis, that the Bjerknes feedback components for the cold events are mirror images of those of warm events, that is, AZM is essentially symmetric. However, Lübbecke and McPhaden (2017) do not rule out the possibility of existence of an asymmetry in forcing of cold and warm events. While the former study did not raise the existence of any asymmetry between the ITCZ (or AMM) and AZM, the latter did not rule out such a possibility. Putting these in context, almost all of these previous studies imply that the anomalous northward (southward) shift of the ITCZ in spring can lead to a cold (warm) AZM event, which implicitly implies a symmetric relation between the ITCZ in spring and AZM. Hence, despite the abovementioned studies, the questions we raised remain unanswered to the best of our knowledge and we attempt to address them in this study. These answers should contribute to the predictability of the monsoon (ISM), especially during non-ENSO AZM years by improving our understanding of the AZM that is shown to influence the ISM (Pottapinjara et al. 2014, 2016).

Pottapinjara et al. (2016) show that from the early signs in the zonal wind and heat content in the equatorial Atlantic in boreal spring, an oncoming AZM event may be foretold that might in turn give us clues about the ISMR one season in advance. However, the causative mechanisms that trigger wind anomaly in the equatorial
Atlantic that is a necessary factor for the development of AZM are not yet fully understood. Understanding different causative mechanisms of AZM events may contribute to the predictability of the ISMR by providing any signals that stretch further back in time giving an advanced warning of a forthcoming AZM event and thus of the impact on ISMR. It may also contribute to the knowledge of different biases that can arise in the coupled models especially those that are used to forecast the monsoon and thereby provide process understanding for the improvement of such models.

\section{Data and methods}

The Hadley Centre Sea Ice and Sea Surface Temperature dataset (HadISST; Rayner et al. 2003) is used in this study. The AZM is characterized by the ATL3 index that is the average of SST anomalies over ATL3 region $\left(3^{\circ} \mathrm{S}-3^{\circ} \mathrm{N}\right.$ and $\left.20^{\circ}-0^{\circ} \mathrm{W}\right)$. A warm (cold) AZM is considered to occur in any year when the June-August average of ATL3 index exceeds (falls below) +1 ( 1$)$ standard deviation (Zebiak 1993; Burls et al. 2012). Following this definition, during the study period (19792013), we identify nine warm AZM events that occurred in 1984, 1987, 1988, 1995, 1996, 1998, 1999, 2008, and 2010 and six cold AZM events in years 1982,1983, 1992, 1994, 1997, and 2005. This list is consistent with our earlier studies (Pottapinjara et al. 2014, 2016). Further, following Foltz and McPhaden (2010), AMM is defined as the difference between SST anomalies averaged over the northern $\left(5^{\circ}-28^{\circ} \mathrm{N}\right.$ and $\left.60^{\circ}-20^{\circ} \mathrm{W}\right)$ and southern $\left(20^{\circ} \mathrm{S}-5^{\circ} \mathrm{N}\right.$ and $\left.30^{\circ} \mathrm{W}-10^{\circ} \mathrm{E}\right)$ tropical Atlantic.

In this study, we focus on the ITCZ movement rather than on AMM as the ITCZ captures different remote influences in addition to that of $A M M$ and its relation to the AZM. The meridional movement of ITCZ is tracked using the latitude of the zero meridional surface wind speed along the longitude of $28^{\circ} \mathrm{W}$ in the latitudinal range of $5^{\circ} \mathrm{S}-20^{\circ} \mathrm{N}$ (Servain et al. 1999). The wind data used are taken from the European Centre for Medium Range Weather Forecasts (ECMWF) interim reanalysis (ERA-Interim) (Dee et al. 2011). The fact that the 


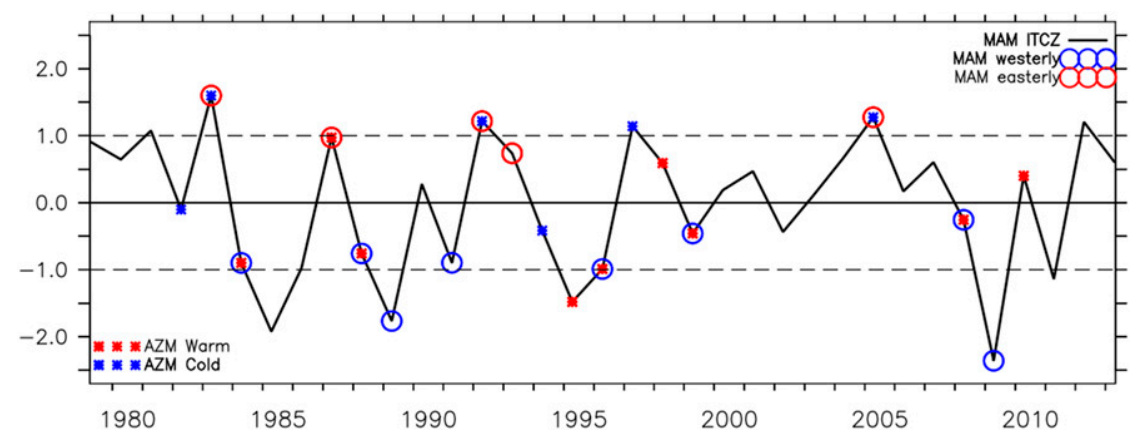

FIG. 1. Interannual variations of anomalous meridional position of ITCZ in March-May (black). The time series is normalized by its standard deviation and \pm 1 standard deviation is indicated by a black dashed line. Whenever the central to western equatorial zonal wind in March-May is sufficiently strong crossing $+0.9(-0.9)$ of its respective standard deviation, i.e., westerly (easterly), it is indicated by blue (red) circles. Whenever the ATL3 SST in JuneAugust crosses $+1(-1)$ of its respective standard deviation, i.e., when there is a warm (cold) AZM event, it is indicated by red (blue) stars.

correlation between ATL3 index and March-May (MAM) ITCZ (-0.34) is marginally higher than that with AMM (-0.31), and the correlation between MAM zonal wind and MAM ITCZ $(-0.82)$ is also larger than that with zonal wind and AMM (-0.73), support our choice to focus on ITCZ instead of AMM (Table 1) to address the questions we have raised earlier. In addition, these significant correlations suggest that understanding the ITCZ movement will give a fresher and potentially a different perspective on the asymmetry in its relation with AZM. The upper-ocean heat content (per unit area) above the $20^{\circ} \mathrm{C}$ isotherm is calculated using ocean temperature data from the EN4 analysis of the Met Office Hadley Centre (Good et al. 2013). Different Bjerknes feedback components are computed and normalized by their respective standard deviations. A twotailed Student's $t$ test is used to determine the statistical significance of the correlation coefficients. In the following, all the seasons used are from the perspective of the Northern Hemisphere, unless mentioned otherwise.

\section{Results}

As mentioned in the introduction, studies such as Servain et al. (1999), Murtugudde et al. (2001), and Foltz and McPhaden (2010) demonstrate the existence of a relationship between the ITCZ (or AMM) and AZM. Indeed, Table 1 shows that during the study period, the correlation between the spring ITCZ position and spring zonal winds is -0.82 , but the correlation between ITCZ and June-August (JJA) ATL 3 index is -0.34 ( 0.33 is the threshold correlation at the 5\% significance level for a sample size of 35). The reduction in correlation implies that not all the meridional excursions of the spring ITCZ lead to AZM events in the following summer despite the variations in the position of ITCZ strongly affecting the spring equatorial zonal winds, a prerequisite for an AZM event.

\section{a. Skewness in the relation between the Atlantic spring ITCZ position and $A Z M$}

To see how many meridional excursions of ITCZ ultimately lead to the AZM events, the interannual variations of spring ITCZ position along with the indicator of the AZM occurrence (listed in the data and methods section) are plotted in Fig. 1. Whenever the spring ITCZ position exceeds its $+1(-1)$ standard deviation, the ITCZ is considered to be located anomalously north (south) from its mean position. From the figure, it can be seen that the ITCZ in spring is anomalously north in six years $(1981,1983,1992,1997,2005$, and 2012) and in four of these years $(1983,1992,1997$, and 2005), the AZM cold events occurred in the following summer. On the other hand, while the ITCZ is anomalously south in six years $(1985,1986,1989,1995,2009$, and 2011), an AZM warm event occurred in the subsequent summer in only one of these years (1995). It is worth mentioning that two AZM warm events that occurred in 1984 and 1996 have a spring ITCZ position just short of the threshold of anomalous southward position, that is, -1 standard deviation. The ratio of AZM cold (warm) events that are preceded by anomalous northward (southward) ITCZ in spring is $4: 6(1: 9)$, that is, $66 \%(11 \%)$. Even if we include the two just-below-the-threshold warm events of 1984 and 1996, the ratio of warm AZM events preceded by southward migration of ITCZ in spring is 3:9 (33\%), which is still significantly less than its counterpart for the cold AZM. Therefore, while an anomalous northward ITCZ in spring tends to give rise to an AZM cold event in the following summer, an anomalous southward 
position of the same is less likely to lead to an AZM warm event. Clearly, there is a skewness in the relation between the position of ITCZ in spring and AZM in the ensuing summer, an important result that has not been reported thus far.

Since the relation between ITCZ and AZM is skewed toward the cold events, to understand different processes involved when the northward displacement of ITCZ in spring leads to an AZM cold event in the following summer, we show the monthly evolution of composite anomalies of different fields in Fig. 2. A positive AMM type of SST configuration (relatively warm in the north and/or cold in the south) during February-May moves the ITCZ anomalously north in spring (MAM). The resultant cross-equatorial winds strengthen the concurrent southeast trades and weaken the northeast trades around the equator in spring. The net result is an enhancement in the strength of easterlies over the equatorial band, a prerequisite for the development of a cold AZM event. The strengthened equatorial easterlies, in turn, result in the increased heat content in the western equatorial Atlantic by deepening the thermocline. An upwelling Kelvin wave propagates to the east to shoal the thermocline and leads to cooler SSTs in the following summer, thus leading to a cold AZM event. As already mentioned in the introduction, the AMM is not the only factor influencing the spring Atlantic ITCZ position but the other factors are not discussed here in Fig. 2 for the sake of simplicity.

It is interesting to inquire as to what gives rise to the skewness in the relation between the position of the ITCZ in spring and AZM. We pose a question as to whether the skewness can be explained by the findings of Richter et al. (2014). Taking monthly means of ITCZ position and equatorial zonal winds, and compositing the winds over each unique ITCZ position during the entire study period, Richter et al. (2014) show that as the ITCZ moves from its southernmost to its northernmost position, equatorial zonal winds remain easterly and grow stronger almost linearly. Given that anomalous equatorial easterlies in spring are a precondition to a cold AZM, if a relation between anomalous spring ITCZ and contemporaneous anomalous equatorial zonal winds holds as presented in Richter et al. (2014); that is, if any anomalous meridional movement of spring ITCZ produces concurrent anomalous equatorial easterlies, it would explain the skewness between spring ITCZ and AZM. But does such a relation exist in reality? The high negative and significant correlation in spring between the ITCZ and central to western equatorial Atlantic zonal winds of -0.82 (Table 1) tells us that the anomalous northward migration of ITCZ in spring is indeed associated with anomalous easterly winds over the central to western equatorial Atlantic. However, a southward migration of the ITCZ in spring is associated with westerly anomalies. A scatterplot between these two quantities (Fig. S1 in the online supplemental material) underscores the same. Therefore, considering the importance of spring wind anomalies for AZMs, the reason for the skewness must lie elsewhere and the interaction of the seasonal cycle and the interannual anomalies may be crucial. The supposed contradiction between the result of Richter et al. (2014) and ours is discussed later in the discussion and conclusions section. The seemingly counterintuitive westerlies associated with the anomalous southward movement of ITCZ in spring can be explained by a careful observation of a spatial map of wind anomalies in the equatorial Atlantic in individual years (figures not shown). In almost all the years when the ITCZ is anomalously south in spring, wind anomalies that are northerly or northeasterly just north of the equator turn and develop a westerly component as they cross the equator. The westerly component just south of the equator is stronger than the easterly component just north of the equator, giving rise to net westerly winds upon averaging in the equatorial band. The mechanisms for these westerly anomalies need further investigation and are beyond the scope of the current study.

The reason for the skewness in fact lies in the peculiar features of climatological movement of the ITCZ in the Atlantic (Fig. 3). From the figure, it may be noted that during January-April the mean position of the ITCZ is relatively close to the equator and the variability of the position of ITCZ is at its highest. The drastic change both in the mean position and the variability occurs during May-June, with the position of the mean ITCZ moving north by about $6^{\circ}$ and the standard deviation falling to about $1 / 3$ of that in April (standard deviation is $1.743^{\circ}$ and $0.576^{\circ}$ latitude in April and June, respectively). During the study period, that is, 1979-2013, the position of ITCZ in spring is anomalously southward in 6 years and in four of those years, winds that are northerly or northeasterly just north of equator develop a strong westerly component upon crossing the equator in spring, as noted above. The maximum of this wind anomaly is centered around $7^{\circ} \mathrm{S}$ with weaker westerlies over the western equatorial Atlantic (WEA) compared to easterlies in spring in the same region when the ITCZ is anomalously north. The westerlies can drive an equatorial downwelling Kelvin wave and remotely deepen the thermocline in the east, if they are sufficiently strong. Nonetheless, the westerlies weaken further in May-June as the climatological ITCZ moves into the Northern Hemisphere and the inherent variability of the ITCZ itself reduces as shown in Fig. 3. This leads to a 
(a)

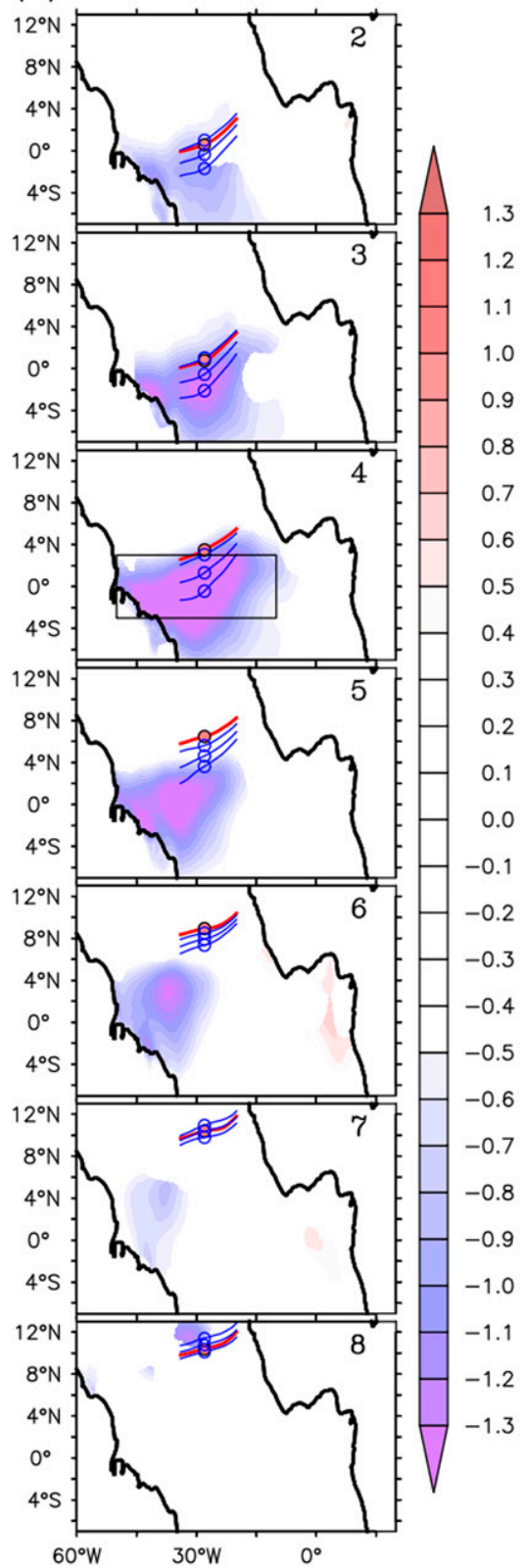

(b)

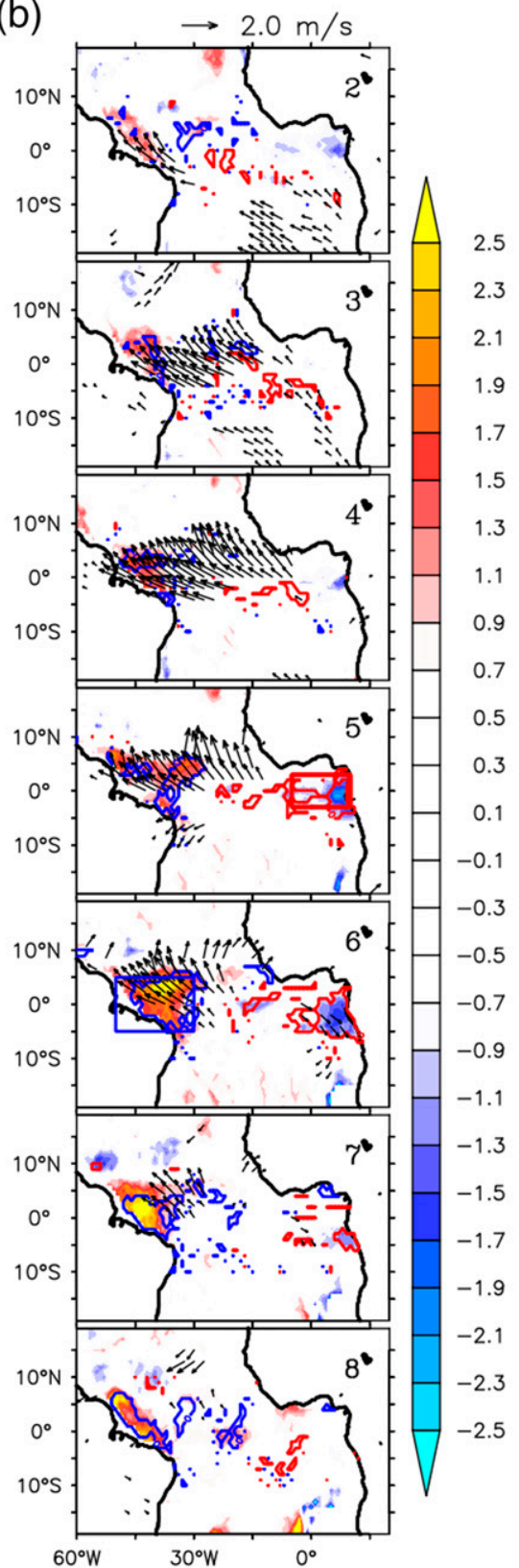

(c)

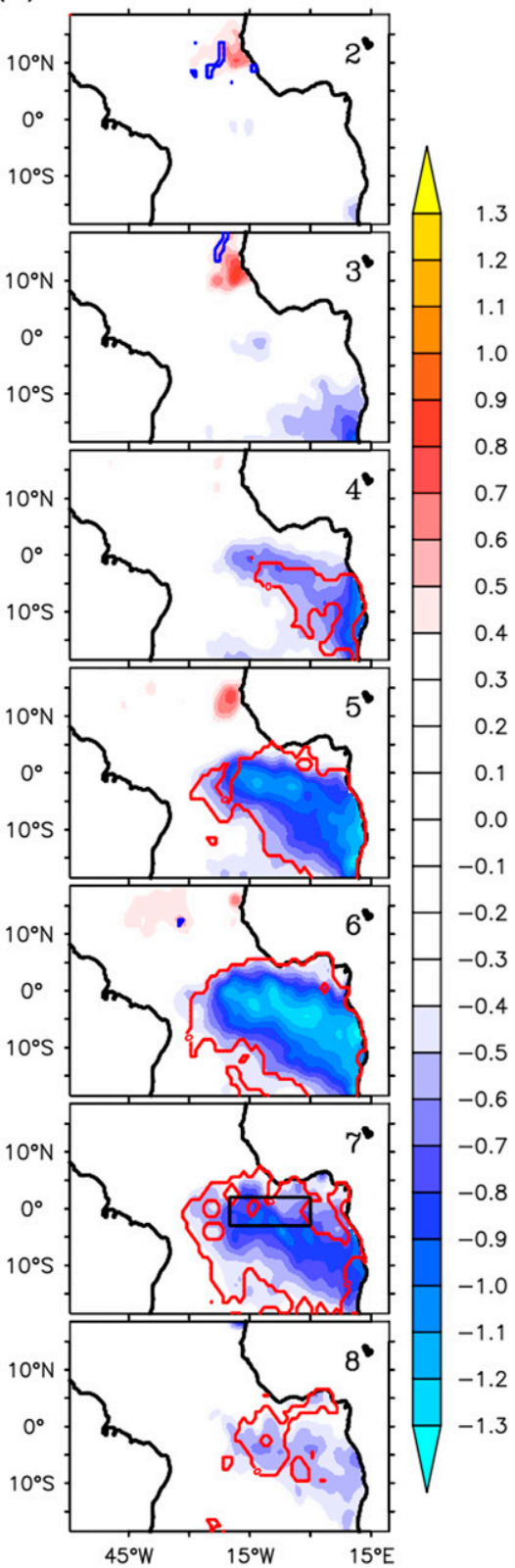

FIG. 2. Monthly (February-August) evolution of composites of (a) ITCZ position (lines) and zonal wind anomalies (shading; $\mathrm{m} \mathrm{s}^{-1}$ ); (b) anomalies of winds (vectors) and heat content (shading; $10^{10} \mathrm{~J} \mathrm{~m}^{-2}$ ); and (c) SST anomalies (shading; ${ }^{\circ} \mathrm{C}$ ) when the spring Atlantic ITCZ is anomalously northward and gives rise to a cold AZM event. In (a), the red line (dot inside a black circle) indicates the ITCZ position at respective longitudes (along $28^{\circ} \mathrm{W}$ ) whereas the blue lines (circle) indicate the envelope of ITCZ variability, i.e., the middle blue line (circle) indicates the climatological ITCZ position in that month, and the top and bottom blue lines (circles) indicate \pm 1 standard deviation of the position from the mean in the same month. The number of calendar month is indicated in each subpanel. Only those zonal winds in (a) and vectors in (b) that are significant at the $5 \%$ level are shown. The significance of heat content anomalies in (b) and SST anomalies in (c) are indicated by line contours. The rectangular boxes in black [in (a); April], red [in (b); May], blue [in (b); June], and thick black [in (c); July] indicate the regions over which anomalies of winds, eastern equatorial Atlantic heat content, western equatorial Atlantic heat content, and SST are averaged, respectively, for use in other analyses.

premature death of a weak incipient warm event resulting ultimately in a very low proportion of AZM warm events surviving into the summer. Figure 4 shows that in the years when spring ITCZ position is anomalously south and winds are westerly over the WEA, the westerlies are not as strong and are less persistent in contrast to those years when the position of ITCZ in spring is anomalously north and winds over WEA are easterly. 


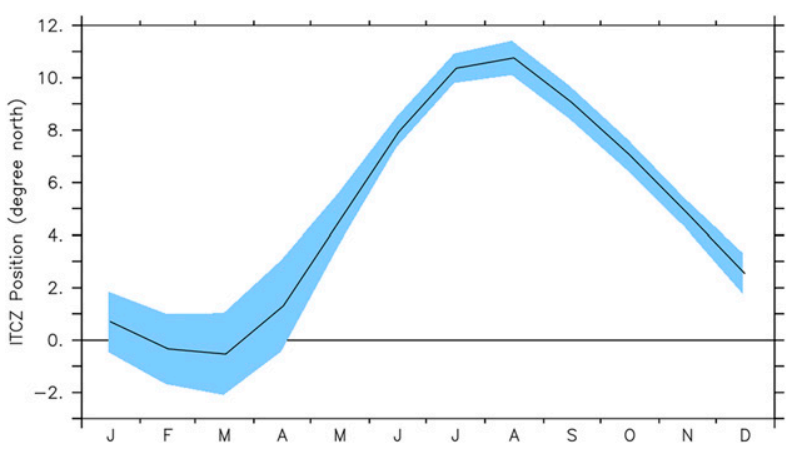

FIG. 3. Monthly evolution of the mean position of the ITCZ in the Atlantic (black line; along $28^{\circ} \mathrm{W} ;{ }^{\circ} \mathrm{N}$ ) with the shading indicating the \pm 1 standard deviation about the mean in the respective months.

In light of the above explanation, a reconsideration of why an anomalous northward movement of ITCZ in spring is highly likely to lead to a cold AZM event is necessary. The fact that the mean position of the ITCZ in February-March is south of the equator implies that even when the ITCZ is anomalously north, the center of maximum easterly wind anomalies is closer to the equator and thus the magnitude of the easterlies over the WEA is stronger than that of the westerly wind anomalies associated with anomalous southward position of the ITCZ (Fig. 4). The strong spring easterlies shoal the thermocline in the east, preparing the ground for an oncoming AZM cold event but weaken in early summer as the mean ITCZ itself moves farther north. Nevertheless, the easterlies persist albeit restricted to an area to the west of $30^{\circ} \mathrm{W}$, helping the cold event survive into the summer. In a nutshell, the skewness in the relation between the position of Atlantic ITCZ in spring and AZM is inherent in the seasonal cycle itself.

From earlier studies (Murtugudde et al. 2001; Pottapinjara et al. 2016; Lübbecke and McPhaden 2017), and our analysis presented in Fig. 2 and Table S1, we identify different factors involved in the mechanism where the anomalous spring migration of ITCZ leads to an AZM in the following summer to be (i) the position of ITCZ in spring (MAM ITCZ), (ii) the concurrent zonal winds averaged over the central to western equatorial Atlantic $\left(3^{\circ} \mathrm{S}-3^{\circ} \mathrm{N}\right.$ and $\left.50^{\circ}-10^{\circ} \mathrm{W}\right)$, (iii) heat content (HC) averaged over the eastern equatorial Atlantic (EEA) in midspring to early summer [April-June (AMJ) EEA $\mathrm{HC} ; 3^{\circ} \mathrm{S}-3^{\circ} \mathrm{N}$ and $\left.5^{\circ} \mathrm{W}-15^{\circ} \mathrm{E}\right]$, (iv) heat content averaged over the western equatorial Atlantic in late spring to midsummer [May-July (MJJ) WEA $\mathrm{HC} ; 5^{\circ} \mathrm{S}-5^{\circ} \mathrm{N}$ and $50^{\circ}-30^{\circ} \mathrm{W}$ ], and (v) SST averaged over the ATL3 region in summer (JJA ATL $3 ; 3^{\circ} \mathrm{S}-2^{\circ} \mathrm{N}$ and $20^{\circ}-0^{\circ} \mathrm{W}$ ). Monthly evolutions of composites of these different factors a)

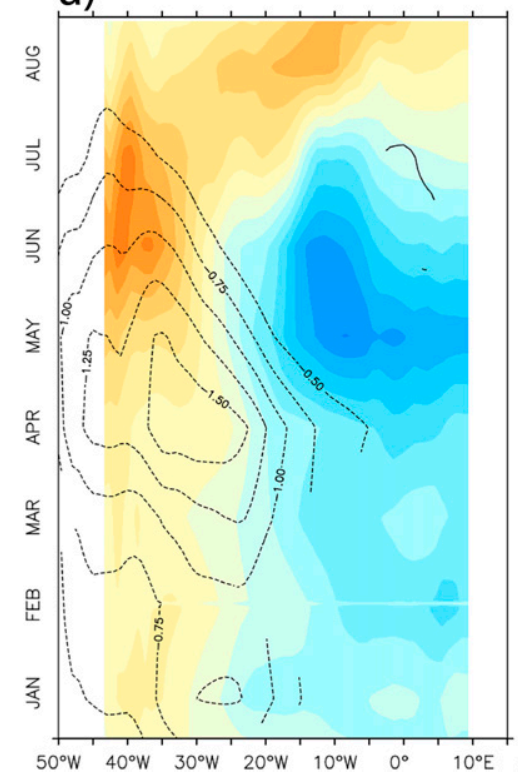

b)

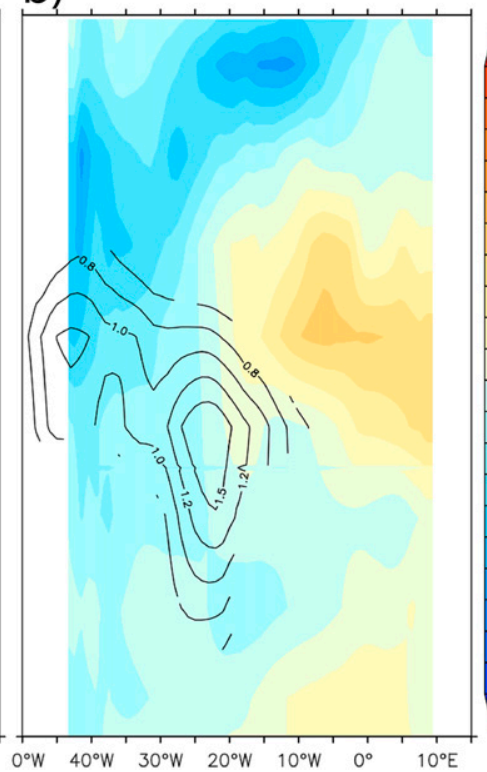

c)

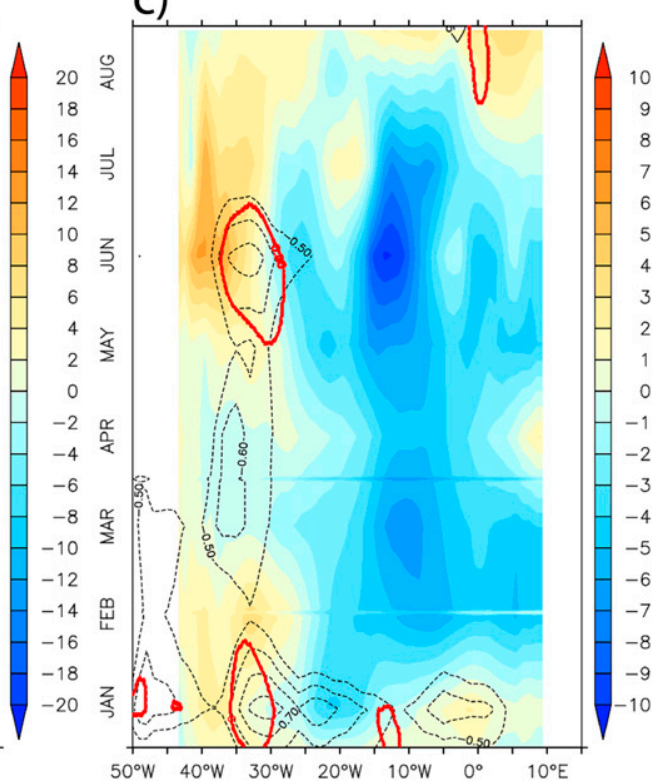

FIG. 4. (a),(b) Hovmöller diagram of the composite of anomalies of thermocline depth (shading) overlaid by zonal winds (contours) over the equator in the Atlantic when the MAM ITCZ is anomalously north (south) and zonal wind anomalies over WEA are easterly (westerly). (c) Hovmöller diagram obtained by adding the anomalies shown in (a) and (b) [= anomalies in (a) - negative of anomalies in (b)], intended to show the dominance of the anomalies in (a) over that in (b). In (a) and (b), only the wind anomalies that are significant at the $5 \%$ level are shown. In (c), the significant wind anomalies are indicated by the contour lines in red. Significance contour lines become discontinuous if the zonal winds between the two ends of a contour are not significant. 


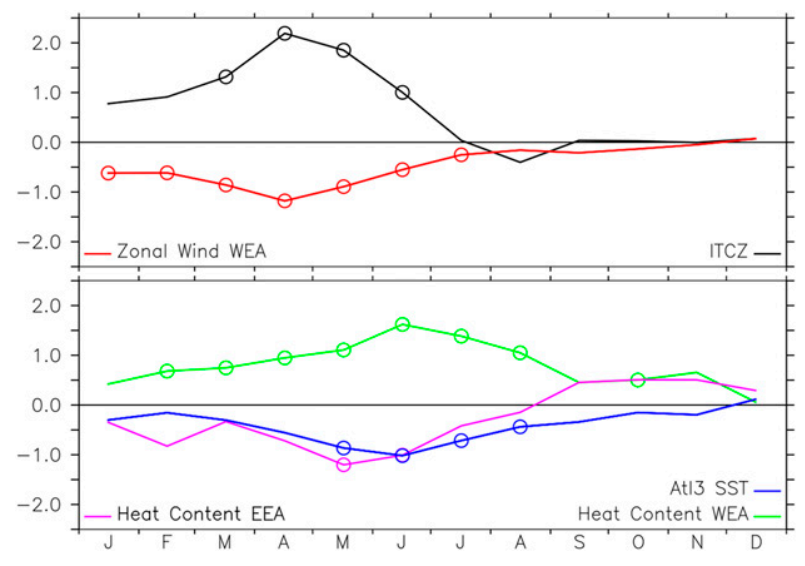

FIG. 5. Monthly evolution of composites of anomalies of (top) zonal winds $\left(\mathrm{m} \mathrm{s}^{-1}\right)$ in the western equatorial Atlantic and position of ITCZ ( ${ }^{\circ}$ latitude) and (bottom) SST averaged over ATL3 region $\left({ }^{\circ} \mathrm{C}\right)$ and heat content $\left(10^{10} \mathrm{~J} \mathrm{~m}^{-2}\right)$ averaged in the western equatorial Atlantic and eastern equatorial Atlantic, composited in the years when the MAM ITCZ is north and leads to the development of a cold AZM event in the subsequent summer. The circles on each line indicate when the respective composite means become significant at the $5 \%$ level.

averaged in their respective regions are presented in Fig. 5 to identify any distinct signatures associated with the cold AZM events that are preceded by northward spring ITCZ. From the figure, it can be seen that the maximum northward displacement of the ITCZ occurs during MAM with the central to western equatorial easterlies peaking simultaneously. The heat content in the eastern equatorial Atlantic reaches its minimum during AMJ while the heat content in the western equatorial Atlantic attains its maximum during MJJ. The SST anomalies in the ATL3 region are at their coldest during JJA. The timings of these different factors agree with the previous studies (Keenlyside and Latif 2007; Pottapinjara et al. 2016) and also yield the highest correlations with the links above and below in the chain of processes (Table S1). These seasonal timings of when different factors become important will be used later to show the distinction of the cold AZM events preceded by northward ITCZ in spring. For the sake of completeness, the counterpart of Fig. 2, that is, the evolution of monthly composites of different fields of all those AZM events that were preceded by an anomalously south ITCZ in spring is shown in Fig. S2.

\section{b. Meridional movement of ITCZ in spring explains strong canonical AZM events}

The Bjerknes feedback is a dominant mechanism that explains AZMs (Keenlyside and Latif 2007) although there are several other mechanisms contributing (Foltz and McPhaden 2010; Zhu et al. 2012; Lübbecke 2013; Lübbecke et al. 2018; Richter et al. 2013). Richter et al. (2013) classify AZM events into those that can and cannot be explained by ENSO-like dynamics. The distinctive criterion that Richter et al. (2013) adopt for the classification is that if a warm (cold) AZM event in summer is preceded by westerly (easterly) winds in the central to western equatorial Atlantic in spring, then it is referred to as a canonical warm (cold) event. On the other hand, if it is preceded by winds of opposite sign, it is called a noncanonical event. It is worth noting that oceanic subsurface changes, which are an important part of the Bjerknes feedback, are not taken into account in this classification. Also, those events that have near neutral winds cannot be covered by their classification. Modifying their definition to account for the above events as well, we classify a "strong canonical" warm (cold) event to be one that is preceded by westerly winds in MarchMay, positive (negative) heat content in the eastern equatorial Atlantic in April-June and negative (positive) heat content in the western equatorial Atlantic in MayJuly. All those events that do not meet this criterion are classified as "non-strong-canonical" warm (cold) events. Note that the respective timings when different Bjerknes components become important are only for a typical AZM event (Keenlyside and Latif 2007). Interannual variations of these different factors are normalized by their respective standard deviations and plotted in Fig. 6. To categorize an AZM event as strong canonical, the amplitude of these factors (with the exception of winds) is required to exceed one respective standard deviation. This condition is relaxed in the case of winds as they tend to be noisy. The threshold of amplitude is lowered to 0.9 times their standard deviation. In addition, the relaxation accommodates several events for which the amplitude of winds falls short of the threshold imposed on all other factors, that is, one standard deviation.

Going by this definition, it can be seen from Fig. 6 that the strong canonical (non-strong-canonical) cold AZM events are 1983, 1992, 1997, and 2005 (1981 and 1994). For every strong canonical cold event, normalized factors clearly exceed one respective standard deviation along with the spring ITCZ position in Fig. 1. The strong canonical (non-strong-canonical) warm events are 1984, 1996, and 2008 (1987, 1988, 1995, 1998, 1999, and 2010). None of the strong canonical warm events have ITCZ in spring located farther southward than the threshold position although the ITCZ was appreciably southward in 1984 and 2008. The proportion of strong canonical cold (warm) AZM events is 4:6 (3:9), that is, 66\% (33\%). In other words, the proportion of strong canonical events is larger in case of cold events than that of warm events. It is interesting to note that all strong canonical 


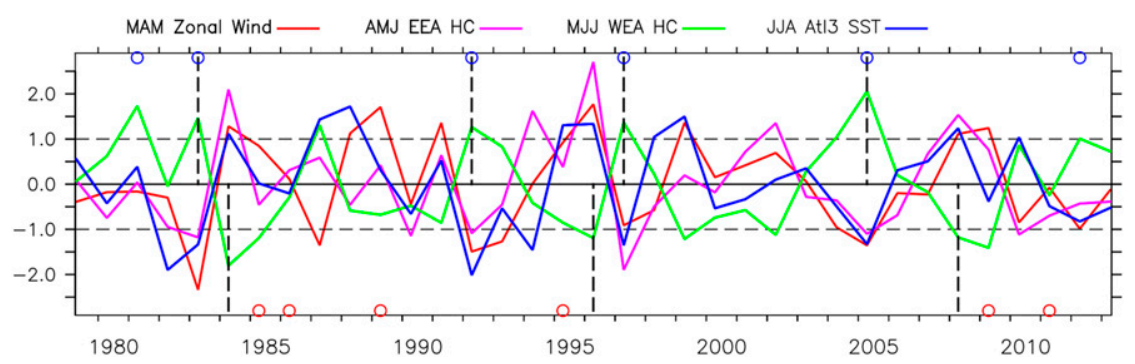

FIG. 6. Interannual variations of anomalies of western equatorial Atlantic zonal winds in March-May (red; $\mathrm{m} \mathrm{s}^{-1}$ ), eastern equatorial Atlantic heat content in April-June (purple; $10^{10} \mathrm{~J} \mathrm{~m}^{-2}$ ), western equatorial Atlantic heat content in May-July (green; $10^{10} \mathrm{~J} \mathrm{~m}^{-2}$ ) and SST in the characteristic ATL3 region in June-August (blue; ${ }^{\circ} \mathrm{C}$ ). Strong canonical cold (warm) events are indicated with black dashed line in upper (lower) portion. All the time series are normalized by their respective standard deviation. Whenever the spring ITCZ crosses $+1(-1)$ standard deviation, i.e., north (south), it is indicated with blue (red) thick circles.

cold AZM events are preceded by northward movement of ITCZ in spring whereas only two out of three strong canonical warm events are preceded by southward movement of ITCZ in spring. The proportion of strong canonical events, either warm or cold, that can be explained by the spring movement of ITCZ is $86 \%$. From this, we may conclude that most of the strong canonical AZM events can be explained by anomalous spring position of ITCZ and this relation is stronger in the case of cold events compared to that of the warm events. This point is also demonstrated by the drop in correlation between anomalous ITCZ position in MAM and JJA ATL3 index. The correlation when the cold events preceded by ITCZ northward movement in spring are included is -0.34 and is significant at the $5 \%$ level (Table 1). The correlation drops to a statistically insignificant -0.13 , when those events are removed. A major reason for the reduction in the correlation may be attributed to changes in the heat content in the western equatorial Atlantic (MJJ WEA HC) as it is the only component whose correlation falls below significance after removing the strong canonical cold AZM events (not shown). It must be clarified that we separate AZM events into strong canonical and non-strong-canonical as opposed to the separation of "canonical" and "noncanonical" of Richter et al. (2013) that is based on Bjerknes feedback mechanism and our classification of non-strong-canonical does not imply that those events cannot be explained by the said mechanism. On a related note, it should also be mentioned that our classification of AZM events into strong canonical and non-strongcanonical events is sensitive to the data product used and the classification of a few events may change. However, it does not alter our result that almost all the strong canonical AZM events can be explained by the spring Atlantic ITCZ movement and that this relation is stronger for the cold AZM events.
It may be noted that not all anomalous northward excursions of ITCZ in spring lead to AZM cold events in summer. There are 2 years (1981 and 2012) in which despite the ITCZ being anomalously north in spring, a cold AZM event did not follow (see supplemental material for details). Although the northward excursion of ITCZ in spring is a necessary condition for the development of a cold event, it is not sufficient unless its position and resulting easterlies over the equatorial Atlantic are sustained throughout spring. In addition, decadal variability of the ITCZ position and oceanic factors may also be important for the ITCZ-AZM relationship. This may potentially explain the decadal changes in the AZM-AMM correlation reported by Murtugudde et al. (2001). However, further investigations will be needed to quantify the low-frequency variability of this asymmetry between ITCZ and AZM interactions.

\section{c. Asymmetry in diversity of causative mechanisms of cold and warm AZM events}

In the previous section, we have shown that most of the strong canonical AZM events are explained by the ITCZ movement in spring and subsequent Bjerknes feedback. It is interesting to explore what other mechanisms may explain the AZM events apart from the ITCZ movement and/or the dominant Bjerknes feedback. As it is difficult to show spatial evolution of each and every event, we present a novel pictorial representation of the evolution of the Bjerknes components of all the AZM events during the study period in Fig. 7. This representation serves multiple purposes: (i) whether a particular event can be explained by the Bjerknes feedback can be conveniently determined; (ii) evolution of multiple events can be summarized in one frame. For an easy interpretation of the figure, tracking of the cold event in 1983 is explained. While 


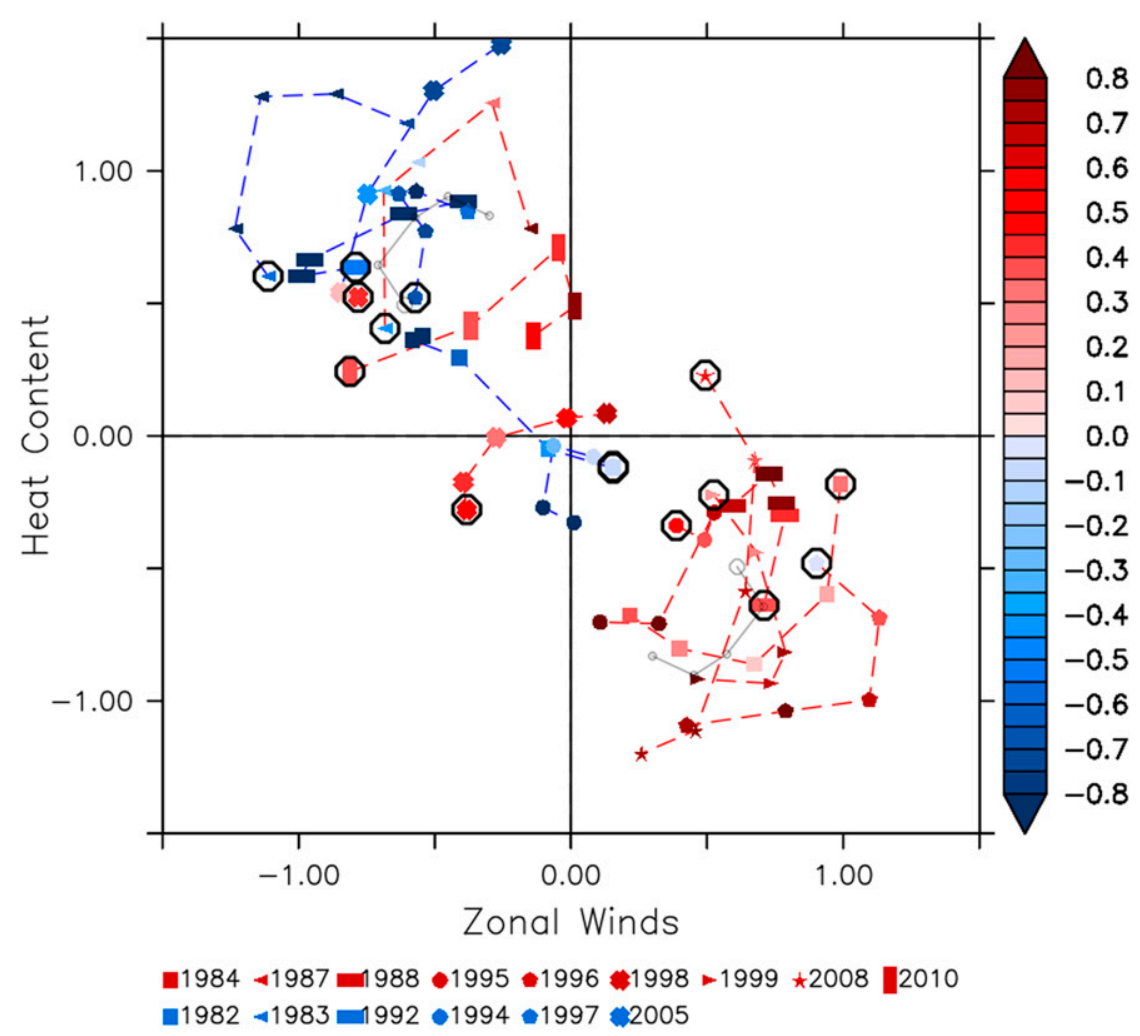

FIG. 7. Evolution of different Bjerknes components during March-July of each AZM event in the phase space of zonal winds averaged over the central to western equatorial Atlantic (abscissa; $\mathrm{m} \mathrm{s}^{-1}$ ) and heat content in the western equatorial Atlantic (ordinate; $10^{10} \mathrm{~J} \mathrm{~m}^{-2}$ ) with the color of each point/symbol representing the SST in the ATL3 region $\left({ }^{\circ} \mathrm{C}\right)$. Different symbols are used to mark different AZM events and the red (blue) dashed lines connecting them indicate a warm (cold) AZM event. The starting point of each year, i.e., March, is indicated by a black circle. The gray line connects the one standard deviation points in the phase space during March-July, and the March point is indicated with a bigger gray circle. This line serves as a reference against which the strength of a particular event can be compared. All the Bjerknes components plotted are smoothed by a 3-month running mean for a better appearance. For the Bjerknes feedback to be considered active all three elements of Keenlyside and Latif (2007) have to be present. While the heat content and zonal wind anomalies are used as the axes, SST in the ATL3 region is shown filling different symbols used to differentiate between the events and is easy to miss. Since only the AZM events that we already know have an SST response (AZM definition is based on ATL3 SST index) are plotted, this representation is adequate to tell us whether or not an AZM event can be explained by the Bjerknes feedback.

the equatorial zonal winds remain almost steady during March-May, the heat content in the western equatorial Atlantic increases. Both the winds and heat content decrease in strength after May. The SST in the ATL3 region reaches its peak in May-June. The movement along the trajectory in a clockwise direction indicates that the changes in the zonal winds precede those in the heat content. From Fig. 7, it can be noted that normally the trajectories of cold (warm) events are in the top-left (bottom right) quadrant. All such events can be explained by Bjerknes mechanism to one degree or another whether preceded by an appropriate ITCZ movement in spring or not. However, there are exceptions: the cold event of 1994 and warm events of 1987, 1998, and 2010. The cold event of 1982 is a slight exception in that its track is close to the origin because of weak Bjerknes components but ultimately moves to the top-left quadrant when the components become strong enough. Apparently, the two exceptions among cold events (1982 and 1994) are also the events that are not preceded by a spring northward movement of ITCZ. This figure is clearly reminiscent of Kessler (2002) and captures similar aspects of the rechargedischarge processes involved in AZM, although the focus there was on whether ENSO is an oscillation or a series of events. A similar question is relevant 
for AZM as well, and we will present that analysis elsewhere.

What are the mechanisms by which cold AZM events form without a northward movement of ITCZ and/or the Bjerknes feedback? As mentioned earlier, the AZM cold events that are not preceded by northward ITCZ in spring occurred in 1982 and 1994. In both of these events, a negative SST anomaly forms because of winds off the equator (either southerly alongshore or easterlies parallel to the equator) and spreads over to the equator to eventually become a cold event (see supplemental material for detailed discussion of the events). Thus, during the study period, most of the cold AZM events are explained by Bjerknes feedback associated with the spring movement of ITCZ and the rest by the wave activity induced by alongshore winds off Angola and/or off-equatorial winds.

The causative mechanisms and timing of the triggers of a warm event appear to be more diverse than that of a cold event. As mentioned earlier, only two out of nine warm events are explained by ITCZ movement in spring and subsequent Bjerknes feedback. The remaining warm events are: 1987,1988,1995, 1999, 2008, and 2010. Most of them can be broadly explained by the Bjerknes feedback mechanism if we do not adhere strictly to the requirement of a strong subsurface response (1988, 1995, 1999, and 2008; Figs. 1 and 6). The exceptions are the warm events of 1998, 1987, and 2010 (see supplemental material for details). Although the Bjerknes feedback mechanism seems to be at the center of most of the warm events, only a few events are triggered by a southward spring transition of ITCZ. On a side note, it is interesting to see that after accounting for the change of center of action as in the case of the cold event of 1994 and the warm event of 1998, trajectories of all the cold events move in a clockwise direction, which means that the changes in the zonal winds precede the changes in heat content (Fig. S3). However, the trajectories of warm events of 1988 and 1998 move in an anticlockwise direction.

Several previous studies have discussed different mechanisms by which a warm AZM event can occur. Richter et al. (2013) show that AZM warm events that cannot be explained by ENSO-like dynamics are driven by a mechanism in which surface wind anomalies just north of the equator induce warm heat content anomalies that are advected toward the equator and propagate to the east. They argue that such warm events are caused by AMM with warm SST anomalies in the TNA. This is different in details compared to the mechanism suggested by Foltz and McPhaden (2010), which involves waves described earlier in the introduction. Zhu et al. (2012) show an interesting relation between the AMM and AZM on a 3-4-yr time scale. The positive heat content anomalies in northern tropical Atlantic resulting from positive AMM, can discharge into the equatorial waveguide when the AMM weakens, and stimulate a warm AZM event about 12-15 months later (the warm event of 1987 is an example of this mechanism but on shorter time scales). Lübbecke (2013) summarizes different mechanisms causing a warm event. Lübbecke et al. (2018) review the important results, mechanisms and viewpoints related to the AZM. From all these previous studies mentioned above and our analysis, it may be concluded that the causative mechanisms of a warm AZM event are more diverse compared to that of a cold event. Our findings here add a finer point via the asymmetry in the ITCZ-AZM interactions. In this study, we are more specifically focused on the asymmetry of cold and warm events related to ITCZ variability and not on proposing any new mechanism for the AZM itself.

\section{Discussion and conclusions}

Several earlier studies have discussed the existence of a relation between the ITCZ position in spring (or $\mathrm{AMM}$ ) in the tropical Atlantic and the AZM in summer, using correlation analyses. However, to the best of our knowledge, none of these studies addressed why the high correlation between the anomalous position of ITCZ and equatorial zonal winds in spring, a prerequisite for the development of an AZM event, does not translate into strong association between the ITCZ position in spring and AZM in summer. By starting from an initial hypothesis that the ITCZ-AZM relation may have a skewness with regard to cold and warm AZM events, we show that the relation between the ITCZ in spring and AZM is stronger for cold AZMs than warm AZMs, with a skew toward cold events (Fig. 8). We further show that the skewness is inherent in the seasonal cycle itself. The weakened and less persistent westerly winds in the western equatorial Atlantic during warm events and the resultant lack of support from the subsurface ocean response, an important factor in the Bjerknes feedback, are argued to result in a weak association between the ITCZ and warm AZM. We also show that the AZM events caused by ITCZ movement are "strongly canonical," that is, associated not only with zonal surface winds in spring but also an oceanic subsurface response in late spring to midsummer.

Further, we observe that the timing and causative mechanisms of a cold AZM event are less diverse than that of a warm event. We infer that the asymmetry in the diversity may be explained by the fact the AZM is phase locked to the seasonal cycle (Keenlyside and Latif 2007; Burls et al. 2012), which is due to the seasonal ITCZ movement (Richter et al. 2014, 2017). Further, the cold 


\section{a) Northward ITCZ}
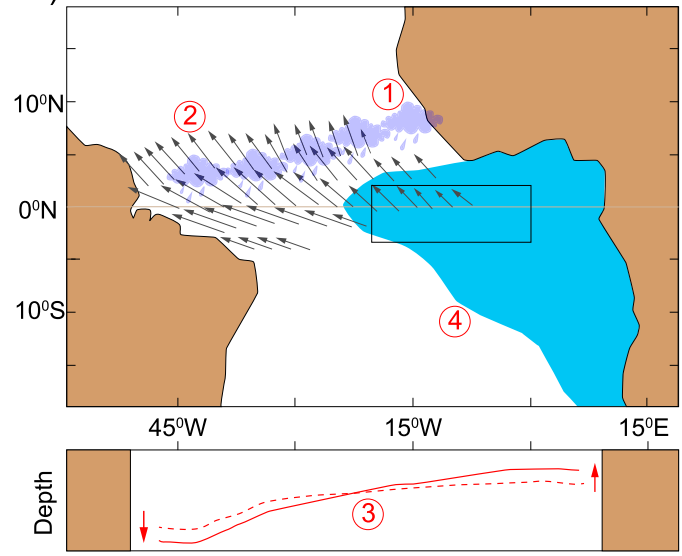

Equatorial Thermocline b) Southward ITCZ

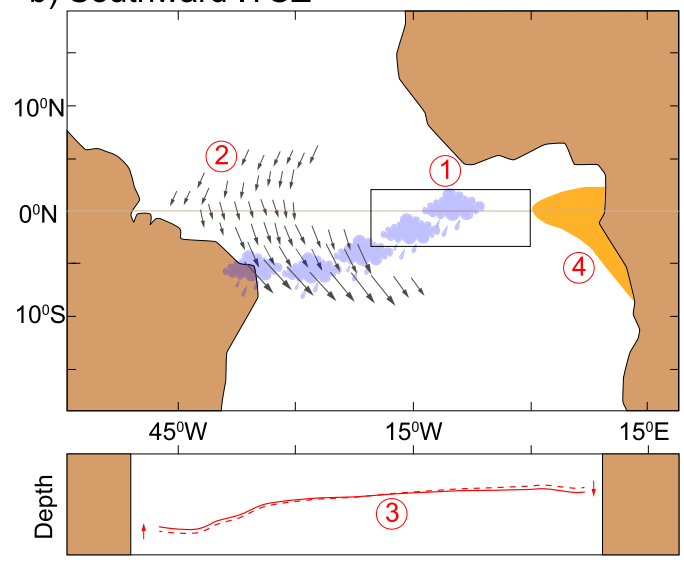

Equatorial Thermocline

FIG. 8. A schematic diagram summarizing the most likely scenario when the Atlantic ITCZ in spring is anomalously (a) north and (b) south. When the Atlantic ITCZ in spring is anomalously north as shown in (a) at point 1, it leads to concurrent anomalous winds that have strong easterly component over the WEA (point 2), which in turn shoals the equatorial thermocline in the east and deepens the same in the west with a delay of 1 or 2 months (point 3 ; dashed line: mean thermocline; thick line: shifted thermocline), finally resulting in a cold AZM event in the following summer (point 4). On the contrary, when the ITCZ in spring is anomalously south as shown in (b) at point 1 , it leads to concurrent anomalous winds that are predominantly northerly in the vicinity of the equator but develop a strong westerly component upon crossing into the south but away from the equator (point 2). The westerly component of the winds in the WEA is so weak that they cause insufficient deepening of equatorial thermocline in the east (point 3) inducing weak warm SST anomalies and thus no warm AZM event (point 4). In summary, while the anomalous northward spring ITCZ leads to a cold AZM event in the following summer most of the times, the converse is less likely and hence the skewness in the relation between spring ITCZ position and AZM. The ATL3 region is marked with a rectangular box. This schematic is only for representative purposes and not to scale.

AZM being simply an enhancement of the climatological condition and the warm AZM being an anomaly in its true sense, may also be important to consider. It should be noted that there are more warm events in the study period than cold events, and thus inadequate sampling may be an issue. However, it must be observed that almost all the studies that propose a different mechanism other than the straightforward Bjerknes feedback do it only for a warm AZM case. We opine that the asymmetry is inherent in the strong association of the AZM with the seasonal cycle. While we have discussed the asymmetry in causative mechanisms of cold and warm AZM events, Lutz et al. (2015) discuss the asymmetry of rainfall response to the cold and warm AZM events. Adapting a different definition of the cold and warm tropical Atlantic SSTs, they show that the effect of the cold and warm events on the rainfall in different regions in Africa is asymmetric in season and magnitude.

Our set goal was to understand the causes for the drop in correlation between the ITCZ in spring and AZM despite a high correlation between ITCZ and equatorial zonal winds in spring, and apparent criticality of these winds for the development of an AZM. However, a related question of why the relation between wind anomalies in spring and SST anomalies in summer is weaker than the correlation between equatorial trades and ITCZ latitude (Table 1) can be also posed. This has been addressed by several studies either overtly or implicitly. Foltz and McPhaden (2010), Lübbecke and McPhaden (2012), and Richter et al. (2013) talk about how spring warm SST anomalies in the TNA can sometimes cause a warm AZM event in the following summer instead of the usual cold AZM event. The positive meridional mode is associated with equatorial easterly winds in boreal spring, which normally is a precondition for a cold AZM. However, in some special cases, via the mechanisms discussed in earlier studies (Foltz and McPhaden 2010; Lübbecke and McPhaden 2012; Richter et al. 2013), warm AZM events can occur, which weakens the relation between the spring equatorial winds and the summer SSTs. On a related note, Chang et al. (2006) talk about how the tropospheric warming over the tropical Atlantic induced by an El Niño destructively interferes with the spring equatorial easterly winds, which leads to a summer SST cooling in the STA. This can contribute to reducing the association between the spring winds and summer SST anomalies. Nonetheless, as shown in Table 1, the correlation between the spring ITCZ position and summer ATL3 index is lower than that between spring WEA zonal winds and summer ATL3 index making our set goal worthwhile. 
A close relation between equatorial zonal winds and position of the ITCZ has been noted in an earlier study by Richter et al. (2014), who show that the equatorial easterlies grow strong almost linearly when the ITCZ is to the north of equator but they are uniformly weak when the ITCZ is in the south; nevertheless, the winds remain easterly throughout. Although their result appears to be at odds with our observation that anomalous northward (southward) movement of ITCZ during spring is associated with concurrent anomalous easterlies (westerlies), it is not in reality, owing to differences in methodology and time period of the two studies. While Richter et al. (2014) average the monthly mean absolute equatorial zonal wind stress over each unique absolute ITCZ position during their entire study period, which represents the mean picture and removes some of the seasonal preferences, we focused on the relation between anomalies of ITCZ and equatorial zonal winds only during spring. Therefore, we posit that our findings are novel in eliciting the asymmetric relation between the spring position of the ITCZ and AZM and its explanation through interaction between the seasonal cycle and interannual anomalies.

We have described different processes involved when an anomalous northward spring ITCZ, which can be influenced by AMM among other things, leads to a cold AZM in the following summer in Fig. 2. Contrary to our intention, the figure might give an impression that a northward ITCZ shift and easterly wind anomalies occur before the development of significant cool SST anomalies in the southeast Atlantic in the late spring to summer, leading to the question of causality: is the AMM a result of anomalous spring ITCZ position rather than a cause? We clarify this apparent contradiction here. Note that Fig. 2 shows the composite of anomalies of different fields including SST and winds for all those cold AZM events preceded by the ITCZ displaced anomalously north in spring. A positive AMM type of SST structure (warm north and/or cool south) during spring is not present in all the composite years, but whenever it is present (in 1997 and 2005) it persists from February followed by a northward displacement of ITCZ in spring and the associated equatorial easterlies (figure not shown). In the composite picture (Fig. 2), the AMM pattern appears weak in the north but strong in the south because AZM has early SST anomalies of the same sign in the south overlapping with that of AMM there but no signal in the north, which adds to the fact that the AMM SST pattern is not present in all the constituent years. The question of causality is also not supported by earlier studies (e.g., Hu and Huang 2006) that show that the development of an AMM event can span from boreal fall to boreal spring preceding the anomalous meridional displacement of ITCZ in spring with the associated equatorial easterlies.

Although AMM is not central to our study, since it is invoked as one of the factors influencing the spring ITCZ position, it must be pointed out that some studies suggest that AMM may not be a coupled mode and its southern and northern lobes may evolve independently (e.g., Yang et al. 2018). The relative importance of the northern and southern flanks of the AMM for the spring ITCZ position may need to be investigated but that is beyond the scope of our present study.

Our observation that causative mechanisms of the cold AZM (counterpart of La Niña in the tropical Atlantic) are less diverse than that of the warm AZM (counterpart of El Niño) is supported by studies about ENSO diversity reporting similar results (Kug and Ham 2011; Ren and Jin 2011; Chen et al. 2015; Ashok et al. 2017). Chen et al. (2015) attribute the cause of asymmetry, irregularity, and extremes of El Niño to westerly wind bursts and also point out that the wind bursts strongly affect El Niño but not La Niña. Capotondi et al. (2015) and Ashok et al. (2017) suggest that while different types of El Niño are distinguishable, the La Niña events are not. Timmermann et al. (2018) also note that La Niña events exhibit less diversity in their spatial patterns compared to El Niño events pointing to an asymmetry in the dynamical processes involved. These results lend a hand to our speculation that cold AZMs have less diversity compared to warm AZMs. We intend to verify the validity of this hypothesis in a future study.

Given that ITCZ movement is also affected by a decaying ENSO, our result together with the relevant previous studies (Kucharski et al. 2008; Pottapinjara et al. 2014; García-Serrano et al. 2017) hint at an interesting linkage between the tropical Pacific and the ISM in a novel way. Previous studies show that a persistent (into spring) yet decaying El Niño can suppress rainfall over the deep tropical Atlantic and move the ITCZ north in spring. The northward (southward) spring ITCZ can cause a cold (warm) AZM event in the following summer, which in turn can enhance (reduce) the rainfall over India. Normally, an El Niño that is active in summer tends to reduce the ISMR. However, an El Niño peaking in the preceding winter and decaying thereafter can enhance the ISMR through the cold AZM, El Niño's reincarnation. This should at least motivate more focused model sensitivity studies to better understand the ITCZ-AZM interaction and its asymmetries.

Acknowledgments. This is a part of the Ph.D. thesis of V.P. We acknowledge two anonymous reviewers whose insightful comments helped improve this paper. The 
encouragement and support of the Director of INCOIS is gratefully acknowledged. R.M. thanks IIT, Bombay, for the position of Visiting Professor, which facilitated discussions on this work. The graphics are generated using PyFerret of PMEL, NOAA. This is INCOIS contribution number 337 and NCPOR contribution number J-04/2019-20.

\section{REFERENCES}

Amaya, D. J., and G. R. Foltz, 2014: Impacts of canonical and Modoki El Niño on tropical Atlantic SST. J. Geophys. Res. Oceans, 119, 777-789, https://doi.org/10.1002/2013JC009476.

Ashok, K., Z. Guan, and T. Yamagata, 2001: Impact of the Indian Ocean dipole on the relationship between the Indian monsoon rainfall and ENSO. Geophys. Res. Lett., 28, 4499-4502, https:// doi.org/10.1029/2001GL013294.

_- M. Shamal, A. K. Sahai, and P. Swapna, 2017: Nonlinearities in the evolutional distinctions between El Niño and La Niña types. J. Geophys. Res. Oceans, 122, 9649-9662, https:// doi.org/10.1002/2017JC013129.

Behera, S. K., R. Krishnan, and T. Yamagata, 1999: Unusual ocean-atmosphere conditions in the tropical Indian Ocean during 1994. Geophys. Res. Lett., 26, 3001-3004, https:// doi.org/10.1029/1999GL010434.

Burls, N., C. Reason, P. Penven, and S. G. Philander, 2012: Energetics of the tropical Atlantic zonal mode. J. Climate, 25, 74427466, https://doi.org/10.1175/JCLI-D-11-00602.1.

Capotondi, A., and Coauthors, 2015: Understanding ENSO diversity. Bull. Amer. Meteor. Soc., 96, 921-938, https://doi.org/ 10.1175/BAMS-D-13-00117.1.

Chang, P., Y. Fang, R. Saravanan, L. Ji, and H. Seidel, 2006: The cause of the fragile relationship between the Pacific El Niño and the Atlantic Niño. Nature, 443, 324-328, https://doi.org/ 10.1038/nature05053.

Chen, D., and Coauthors, 2015: Strong influence of westerly wind bursts on El Niño diversity. Nat. Geosci., 8, 339-345, https:// doi.org/10.1038/ngeo2399.

Chiang, J. C. H., and D. J. Vimont, 2004: Analogous Pacific and Atlantic meridional modes of tropical atmosphere-ocean variability. J. Climate, 17, 4143-4158, https://doi.org/10.1175/ JCLI4953.1.

_- Y. Kushnir, and A. Giannini, 2002: Deconstructing Atlantic intertropical convergence zone variability: Influence of the local cross-equatorial sea surface temperature gradient and remote forcing from the eastern equatorial Pacific. J. Geophys. Res., 107, 4004, https://doi.org/10.1029/2000JD000307.

Czaja, A., and C. Frankignoul, 2002: Observed impact of Atlantic SST anomalies on the North Atlantic oscillation. J. Climate, 15, 606-623, https://doi.org/10.1175/1520-0442(2002)015<0606: OIOASA $>2.0 . \mathrm{CO} ; 2$.

_ P. Van der Vaart, and J. Marshall, 2002: A diagnostic study of the role of remote forcing in tropical Atlantic variability. J. Climate, 15, 3280-3290, https://doi.org/10.1175/15200442(2002)015<3280:ADSOTR > 2.0.CO;2.

Dee, D. P., and Coauthors, 2011: The ERA-Interim reanalysis: Configuration and performance of the data assimilation system. Quart. J. Roy. Meteor. Soc., 137, 553-597, https://doi.org/ 10.1002/qj.828.

Enfield, D. B., and D. A. Mayer, 1997: Tropical Atlantic sea surface temperature variability and its relation to El Niño-Southern
Oscillation. J. Geophys. Res., 102, 929-945, https://doi.org/ 10.1029/96JC03296.

Foltz, G. R., and M. J. McPhaden, 2010: Interaction between the Atlantic meridional and Niño modes. Geophys. Res. Lett., 37 , L18604, https://doi.org/10.1029/2010GL044001.

García-Serrano, J., C. Cassou, H. Douville, A. Giannini, and F. J. Doblas-Reyes, 2017: Revisiting the ENSO teleconnection to the tropical North Atlantic. J. Climate, 30, 6945-6957, https:// doi.org/10.1175/JCLI-D-16-0641.1.

Giannini, A., Y. Kushnir, M. A. Cane, A. Giannini, Y. Kushnir, and M. A. Cane, 2000: Interannual variability of Caribbean rainfall, ENSO, and the Atlantic Ocean. J. Climate, 13, 297-311, https://doi.org/10.1175/1520-0442(2000)013<0297: IVOCRE $>2.0 . \mathrm{CO} ; 2$.

Good, S. A., M. J. Martin, and N. A. Rayner, 2013: EN4: Quality controlled ocean temperature and salinity profiles and monthly objective analyses with uncertainty estimates. J. Geophys. Res. Oceans, 118, 6704-6716, https://doi.org/ 10.1002/2013JC009067.

Ham, Y.-G., J.-S. Kug, and J.-Y. Park, 2013: Two distinct roles of Atlantic SSTs in ENSO variability: North tropical Atlantic SST and Atlantic Niño. Geophys. Res. Lett., 40, 4012-4017, https://doi.org/10.1002/grl.50729.

Hu, Z.-Z., and B. Huang, 2006: Physical processes associated with the tropical Atlantic SST meridional gradient. J. Climate, 19, 5500-5517, https://doi.org/10.1175/JCLI3923.1.

Huang, B., 2004: Remotely forced variability in the tropical Atlantic Ocean. Climate Dyn., 23, 133-152, https://doi.org/ 10.1007/s00382-004-0443-8.

Keenlyside, N. S., and M. Latif, 2007: Understanding equatorial Atlantic interannual variability. J. Climate, 20, 131-142, https:// doi.org/10.1175/JCLI3992.1.

Keshavamurty, R., 1982: Response of the atmosphere to sea surface temperature anomalies over the equatorial Pacific and the teleconnections of the Southern Oscillation. J. Atmos. Sci., 39, 1241-1259, https://doi.org/10.1175/1520-0469(1982)039<1241: ROTATS $>2.0 . \mathrm{CO} ; 2$.

Kessler, W. S., 2002: Is ENSO a cycle or a series of events? Geophys. Res. Lett., 29, 2125, https://doi.org/10.1029/2002GL015924.

Kucharski, F., A. Bracco, J. H. Yoo, and F. Molteni, 2008: Atlantic forced component of the Indian monsoon interannual variability. Geophys. Res. Lett., 35, L04706, https://oi.org/ 10.1029/2007GL033037.

,,,--- A. M. Tompkins, L. Feudale, and P. Ruti, 2009: A Gill-Matsuno-type mechanism explains the tropical Atlantic influence on African and Indian monsoon rainfall. Quart. J. Roy. Meteor. Soc., 135, 569-579, https://doi.org/10.1002/qj.406.

_ - and Coauthors, 2016: The teleconnection of the tropical Atlantic to Indo-Pacific sea surface temperatures on interannual to centennial time scales: A review of recent findings. Atmosphere, 7, 29, https://doi.org/10.3390/atmos7020029.

Kug, J. S., and Y. G. Ham, 2011: Are there two types of La Nina? Geophys. Res. Lett., 38, L16704, https://doi.org/10.1029/ 2011 GL048237.

Lee, S. K., D. B. Enfield, and C. Wang, 2008: Why do some El Niños have no impact on tropical North Atlantic SST? Geophys. Res. Lett., 35, 1968-1969, https://doi.org/10.1029/ 2008 GL034734.

Lübbecke, J. F., 2013: Tropical Atlantic warm events. Nat. Geosci., 6, 22-23, https://doi.org/10.1038/ngeo1685.

_ , and M. J. McPhaden, 2012: On the inconsistent relationship between Pacific and Atlantic Niños. J. Climate, 25, 4294-4303, https://doi.org/10.1175/JCLI-D-11-00553.1. 
— , and - 2017: Symmetry of the Atlantic Niño mode. Geophys. Res. Lett., 44, 965-973, https://doi.org/10.1002/ 2016GL071829.

—, B. Rodríguez-Fonseca, I. Richter, M. Martín-Rey, T. Losada, I. Polo, and N. S. Keenlyside, 2018: Equatorial Atlantic variability-Modes, mechanisms, and global teleconnections. Wiley Interdiscip. Rev.: Climate Change, 9, e527, https://doi.org/ 10.1002/wcc.527.

Lutz, K., J. Jacobeit, and J. Rathmann, 2015: Atlantic warm and cold water events and impact on African west coast precipitation. Int. J. Climatol., 35, 128-141, https://doi.org/10.1002/ joc.3969.

Martin, M., B. Rodriguez-Fonseca, and I. Polo, 2014: Atlantic opportunities for ENSO prediction. Geophys. Res. Lett., $\mathbf{4 2}$ 6802-6810, https://doi.org/10.1002/2015GL065062.

Mooley, D. A., and B. Parthasarathy, 1984: Indian summer monsoon and the east equatorial Pacific sea surface temperature. Atmos.-Ocean, 22, 23-35, https://doi.org/10.1080/07055900. 1984.9649182.

Murtugudde, R. G., J. Ballabrera-Poy, J. Beauchamp, and A. J. Busalacchi, 2001: Relationship between zonal and meridional modes in the tropical Atlantic. Geophys. Res. Lett., 28, 4463 4466, https://doi.org/10.1029/2001GL013407.

Neelin, J. D., and H. Su, 2005: Moist teleconnection mechanisms for the tropical South American and Atlantic sector. J. Climate, 18, 3928-3950, https://doi.org/10.1175/JCLI3517.1.

Nobre, P., and J. Shukla, 1996: Variations of sea surface temperature, wind stress, and rainfall over the tropical Atlantic and South America. J. Climate, 9, 2464-2479, https://doi.org/ 10.1175/1520-0442(1996)009<2464:VOSSTW >2.0.CO;2.

Philander, S. G. H., J. Holton, and R. Dmowska, 1989: El Niño, La Niña, and the Southern Oscillation. 1st ed. Academic Press, $293 \mathrm{pp}$.

Pottapinjara, V., M. S. Girishkumar, M. Ravichandran, and R. Murtugudde, 2014: Influence of the Atlantic zonal mode on monsoon depressions in the Bay of Bengal during boreal summer. J. Geophys. Res. Atmos., 119, 6456-6469, https:// doi.org/10.1002/2014JD021494.

,-- S. Sivareddy, M. Ravichandran, and R. Murtugudde, 2016: Relation between the upper ocean heat content in the equatorial Atlantic during boreal spring and the Indian monsoon rainfall during June-September. Int. J. Climatol., 36, 2469-2480, https://doi.org/10.1002/joc.4506.

Rayner, N. A., D. E. Parker, E. B. Horton, C. K. Folland, L. V. Alexander, D. P. Rowell, E. C. Kent, and A. Kaplan, 2003: Global analyses of sea surface temperature, sea ice, and night marine air temperature since the late nineteenth century. J. Geophys. Res., 108, 4407, https://doi.org/10.1029/2002JD002670.

Ren, H. L., and F. F. Jin, 2011: Niño indices for two types of ENSO. Geophys. Res. Lett., 38, L04704, https://doi.org/10.1029/ 2010 GL046031.

Richter, I., S. K. Behera, Y. Masumoto, B. Taguchi, H. Sasaki, and T. Yamagata, 2013: Multiple causes of interannual sea surface temperature variability in the equatorial Atlantic Ocean. Nat. Geosci., 6, 43-47, https://doi.org/10.1038/ngeo1660.

- , S.-P. Xie, S. K. Behera, T. Doi, and Y. Masumoto, 2014: Equatorial Atlantic variability and its relation to mean state biases in CMIP5. Climate Dyn., 42, 171-188, https://doi.org/ 10.1007/s00382-012-1624-5.

,,- Y. Morioka, T. Doi, B. Taguchi, and S. Behera, 2017: Phase locking of equatorial Atlantic variability through the seasonal migration of the ITCZ. Climate Dyn., 48, 3615-3629, https://doi.org/10.1007/s00382-016-3289-y.

Rodríguez-Fonseca, B., I. Polo, J. García-Serrano, T. Losada, E. Mohino, C. R. Mechoso, and F. Kucharski, 2009: Are Atlantic Niños enhancing Pacific ENSO events in recent decades? Geophys. Res. Lett., 36, L20705, https://doi.org/10.1029/ 2009GL040048.

Servain, J., I. Wainer, J. P. McCreary, and A. Dessier, 1999: Relationship between the equatorial and meridional modes of climatic variability in the tropical Atlantic. Geophys. Res. Lett., 26, 485-488, https://doi.org/10.1029/1999GL900014.

Sikka, D. R., 1980: Some aspects of the large-scale fluctuations of summer monsoon rainfall over India in relation to fluctuations in the planetary and regional scale circulation parameters. Proc. Ind. Acad. Sci. Earth Planet. Sci., 89, 179-195, https:// doi.org/10.1007/BF02913749.

Slingo, J. M., and H. Annamalai, 2000: The El Niño of the century and the response of the Indian summer monsoon. Mon. Wea. Rev., 128, 1778-1797, https://doi.org/10.1175/1520-0493(2000) $128<1778$ :TENOOT $>2.0$. CO; 2 .

Timmermann, A., and Coauthors, 2018: El Niño-Southern Oscillation complexity. Nature, 559, 535-545, https://doi.org/ 10.1038/s41586-018-0252-6.

Wang, C., F. Kucharski, R. Barimalala, and A. Bracco, 2009: Teleconnections of the tropical Atlantic to the tropical Indian and Pacific Oceans: A review of recent findings. Meteor. Z., 18, 445-454, https://doi.org/10.1127/0941-2948/2009/0394.

Webster, P., V. Magana, T. Palmer, J. Shukla, R. Tomas, Y. Yanai, and T. Yasunari, 1998: Monsoons: Processes, predictability, and the prospects for prediction. J. Geophys. Res., 103, 14 45114 510, https://doi.org/10.1029/97JC02719.

Wu, L., and Z. Liu, 2002: Is tropical Atlantic variability driven by the North Atlantic oscillation? Geophys. Res. Lett., 29, 29-32, https://doi.org/10.1029/2002GL014939.

Xie, S.-P., and J. A. Carton, 2004: Tropical Atlantic variability: Patterns, mechanisms, and impacts. Earth's Climate: The Ocean-Atmosphere Interaction, Geophys. Monogr., Vol. 147, Amer. Geophys. Union, https://doi.org/10.1029/ $147 \mathrm{GM} 07$.

Yadav, R. K., 2017: On the relationship between east equatorial Atlantic SST and ISM through Eurasian wave. Climate Dyn., 48, 281-295, https://doi.org/10.1007/s00382-016-3074-y.

Yang, Y., S.-P. Xie, L. Wu, Y. Kosaka, and J. Li, 2018: ENSO forced and local variability of North tropical Atlantic SST: Model simulations and biases. Climate Dyn., 51, 4511-4524, https://doi.org/10.1007/s00382-017-3679-9.

Zebiak, S. E., 1993: Air-sea interaction in the equatorial Atlantic region. J. Climate, 6, 1567-1586, https://doi.org/10.1175/15200442(1993)006<1567:AIITEA >2.0.CO;2.

Zhu, J., B. Huang, and Z. Wu, 2012: The role of ocean dynamics in the interaction between the Atlantic meridional and equatorial modes. J. Climate, 25, 3583-3598, https://doi.org/10.1175/ JCLI-D-11-00364.1. 